\title{
TECNOLOGIAS MÓVEIS E O ESTUDO DA TABUADA: REFLEXÕES SOBRE O USO DO JOGO MATH DUEL
}

\author{
Mobile Technologies and the Study of Multiplication Tables: Reflections about the \\ Use of the Game Math Duel
}

\author{
Camila Dorneles da Rosa* \\ Valdir Pretto** \\ Ana Marli Bulegon ${ }^{* * * *}$
}

\begin{abstract}
Resumo: O presente trabalho tem por objetivo investigar as percepções de um grupo de acadêmicas de um curso de Pedagogia sobre o uso do jogo Math Duel como ferramenta para o ensino da tabuada. É válido destacar que esse estudo é parte de uma pesquisa de mestrado que teve por objetivo investigar contribuições das tecnologias móveis para o ensino da tabuada. Assim, ao investigar essas percepções nesse estudo, pretendeu-se que os momentos de interação com o aplicativo fizessem parte do processo formativo das acadêmicas, contribuindo para sua futura prática docente. A pesquisa foi desenvolvida em uma turma do sexto semestre do curso de Pedagogia, composta por oito mulheres, contando por uma parte de interação com o jogo e posteriormente respondendo um questionário sobre o uso do mesmo. As participantes demonstraram motivação, alegria e satisfação em manuseá-lo, mesmo aquelas que não estavam acostumadas a usar as tecnologias móveis. Depois de experimentarem o jogo com seus estudantes de anos iniciais do Ensino Fundamental elas afirmam que se pode utilizar jogos digitais para desenvolver e/ou verificar a aprendizagem dos conceitos de tabuada. Para elas o jogo é divertido e envolvente, estimula o cálculo mental, o que permite aprender e resolver as operações da tabuada de forma rápida e eficaz. Concluise, com isso, que os jogos digitais despertam a atenção e concentração dos estudantes a partir do envolvimento deles em cada fase/etapa e o sucesso obtido em cada uma delas gera satisfação, o que potencializa a aprendizagem da tabuada para além dos espaços escolares.
\end{abstract}

Palavras-chave: Ensino de Matemática. Celular. Formação de Professores. Jogos digitais.

\begin{abstract}
The present work aims to investigate the perceptions of a group of academics from a Pedagogy course on the use of the game Math Duel as a tool for teaching multiplication tables. It is noteworthy that this study is part of a master's research which aimed to investigate contributions of mobile technologies to the teaching of multiplication tables. Thus, by investigating these perceptions in this study, it was intended that the moments of interaction with the application were considered as part of the teachers' formation process, contributing to their future teaching practice. The research was developed in a class of the sixth semester of the Pedagogy course, made up by eight women, involving the interaction with the

\footnotetext{
* Mestra em Ensino de Ciências e Matemática. Professora da Educação Básica do Estado do Rio Grande do Sul. camiladornelesdarosa@gmail.com.

*** Doutor em Educação. Professor do Programa de Pós-graduação em Ensino de Ciências e Matemática - UFN. prettov@gmail.com.

**** Doutora em Informática na Educação. Professora do Programa de Pós-graduação em Ensino de Ciências e Matemática - UFN. anabulegon@unifra.br.
}

\# Tear: Revista de Educação Ciência e Tecnologia, v.8, n.2, 2019. 
application and after the answering of a questionnaire about its use. Participants showed motivation, joy and satisfaction in handling it, even those who were not used to using mobile technologies in school activities. After experimenting with their early-elementary school students, they claim that digital games can be used to develop and / or verify the learning of multiplication tables, as the game is fun and engaging, stimulates mental calculation, which allows you to learn and solve the multiplication table operations quickly and effectively. Thus, it is concluded that digital games arouse students' attention and concentration from their involvement in each phase / stage and the success obtained in each one of them generates satisfaction, which enhances the learning of the multiplication tables beyond the school spaces.

Keywords: Mathematics Teaching. Smartphones. Teacher's Formation. Games.

\title{
1 Introdução
}

As pesquisas envolvendo a temática da formação de professores têm sido constantes na área da Educação Matemática, realizadas com docentes da Educação Infantil ao Ensino Superior; inseridas na formação inicial e continuada destes sujeitos.

Nesse contexto formativo, acredita-se que o professor deva estar em constante aprendizado para que possa compartilhar seus conhecimentos da melhor forma possível com seus estudantes, planejar e executar aulas interessantes, a fim de despertar sua curiosidade e promover a aprendizagem.

O professor tem, em sua profissão, a responsabilidade e o compromisso de formar cidadãos críticos e reflexivos para uma vida em sociedade, orientando caminhos e mostrando o conhecimento científico. Assim, é necessário que esse profissional acompanhe as mudanças que ocorrem ao seu redor, a exemplo das tecnologias, e seja receptivo às novas formas de ensinar e aprender.

Conforme Imbernón (2011):

\begin{abstract}
A profissão docente comporta um conhecimento pedagógico específico, um compromisso ético e moral e a necessidade de dividir responsabilidade com outros agentes sociais, já que exerce influência sobre outros seres humanos e, portanto, não pode nem deve ser uma profissão meramente técnica de 'especialistas infalíveis’ que transmitem unicamente conhecimentos acadêmicos (p. 30).
\end{abstract}

Nesse sentido, Moran (2013) destaca que além de ensinar, o papel da educação envolve integrar todas as dimensões da vida do ser humano, a fim de modificar a sociedade em torno dos que aprendem.

Um dos grandes desafios do educador é ajudar a tornar a informação significativa. Moran (2013) destaca que os professores devem inovar nas suas aulas, pois muitas formas de ensinar já não fazem mais sentido e, nesse caso, é preciso propor novas formas de apresentar os conteúdos.

Nossos estudantes de hoje possuem uma facilidade em se envolver com as tecnologias, seja por sua curiosidade natural, ou por não terem medo de novidades e, assim, dentro de suas possibilidades incorporam esses recursos e linguagens ao seu dia a dia (ARAÚJO, 2005). Com isso, faz-se necessário que os professores estejam capacitados e

\# Tear: Revista de Educação Ciência e Tecnologia, v.8, n.2, 2019. 
abertos para a mudança, pois conhecer e saber como trabalhar com os recursos tecnológicos pode auxiliar no desenvolvimento dos conteúdos, visto que o uso das tecnologias móveis pode permitir uma aula mais dinâmica e atrativa.

Levando em consideração todos os fatores elencados anteriormente e, a necessidade da inserção de tecnologias na formação de professores (PENTEADO, 2000), esse trabalho relata parte de uma pesquisa de mestrado que teve por objetivo analisar a importância e as contribuições do uso das tecnologias móveis, como recurso pedagógico, para o ensino da tabuada nos anos iniciais do Ensino Fundamental.

Como esse texto é um recorte de tal pesquisa, tem-se por objetivo para esse trabalho, investigar as percepções de acadêmicas de um curso de Pedagogia sobre o uso do jogo Math Duel $^{1}$ para o ensino da tabuada. Ao investigar essas percepções, pretende-se que os momentos de interação com o aplicativo façam parte do processo formativo das professoras, contribuindo para sua futura prática docente.

\title{
2 O uso das tecnologias móveis como recursos auxiliares para as aulas de Matemática
}

Dentre as Tecnologias da Informação e Comunicação (TIC), uma questão importante é o uso das tecnologias móveis ${ }^{2}$ em sala de aula, embora muitos professores ainda sejam resistentes a utilização desses recursos, pois o smartphone faz parte deles. Gouvêa e Pereira (2015, p. 41) afirmam que "ainda há total resistência por parte da maioria dos professores em aceitar que os estudantes façam uso de uma dessas importantes tecnologias: o celular. Talvez por relacionar o mesmo apenas à geração de problemas".

Com a expansão dos aparelhos móveis, a tecnologia móvel passou a ser uma promessa especial para a educação, pois facilita a comunicação de professores e estudantes mesmo fora da escola. Atualmente, são muito comuns os grupos virtuais que estudantes e professores participam, por exemplo, grupos nas redes sociais Facebook e WhatsApp. Outra questão importante é a pesquisa em sites e redes sociais utilizando os smartphones, que proporciona uma interação dos estudantes com os conhecimentos compartilhados pelos usuários, dentre eles os professores, visto que a sociedade que está cada vez mais conectada à Internet.

Entretanto, concorda-se com Recchi e Martins (2016, p. 297), quando afirmam:

\begin{abstract}
A presença do professor em sala de aula continua sendo de suma importância, o que mudou foi a forma como o conhecimento foi e é trabalhado em sala de aula e os materiais didáticos utilizados, antes sob a forma de livros e cartilhas e agora utilizando mídias digitais, softwares, vídeos, etc. Ressaltamos que o papel do aluno também se modificou, agora como autônomo de sua aprendizagem, desenvolvendo seu senso crítico.
\end{abstract}

Acredita-se que o professor deva interligar o saber que o estudante já possui, em relação ao uso das tecnologias, e o conhecimento científico que está sendo trabalhado em

\footnotetext{
${ }^{1}$ Disponível em:

https://play.google.com/store/apps/details?id=com.mathduel2playersgame.mathgame\&hl=pt_BR. Acesso em: 14 jun. 2018.

${ }^{2}$ Utiliza-se o termo tecnologias móveis quando se trata de dispositivos que possuem portabilidade e que podem ser usados quando se está em movimento.
}

\# Tear: Revista de Educação Ciência e Tecnologia, v.8, n.2, 2019. 
sala de aula. Na maioria das vezes, os estudantes não utilizam (ou não sabem utilizar) as tecnologias para fins educacionais. Então, o professor precisa mediar esse uso e apresentar as inúmeras possibilidades de aprendizado existentes.

Nesta pesquisa, as tecnologias móveis utilizadas foram os tablets e os smartphones. Dessa forma, discute-se o trabalho com esses aparelhos em sala de aula e as contribuições que estes podem trazer para o ensino da Matemática.

\subsection{Smartphones}

A definição de smartphone não é única, visto que os fabricantes do mesmo não conseguem chegar a um consenso. De acordo com Rodrigues (2009, p.19), "pelas funcionalidades disponíveis e diversas definições, pode-se classificar os smartphones como dispositivos programáveis que convergem mobilidade e conectividade". O autor comenta que, de certo modo, pode parecer superficial essa classificação, mas os avanços tecnológicos impedem que seja possível a listagem de um conjunto único de características para que se tenha uma única definição do termo (RODRIGUES, 2009).

Com o crescimento das tecnologias móveis e da infraestrutura da internet, os smartphones vêm ganhando a confiança e a preferência dos brasileiros e já é difícil encontrar pessoas que não façam uso deste dispositivo. Até porque os smartphones substituíram um simples dispositivo de telefonia para um computador no seu bolso. Hoje eles incluem serviços de telefonia, câmeras fotográficas, ferramentas de escrita, áudio e vídeo, calendário, agenda, aplicativos de redes sociais, localização espacial, de bancos, sensor climático, rádio, biblioteca de músicas, player de vídeos, entre outros.

Com isso, Romanello (2016, p. 8) expõe que "obteve-se, como consequência, a invasão desses dispositivos na escola refletindo de forma negativa dentro da sala de aula. Diante dessa situação, é possível perceber que a sala de aula já está sendo atingida pelas tecnologias". Portanto, é necessário que os professores e a equipe gestora das escolas tenham conhecimento de como utilizar esses aparelhos de forma que os auxilie no processo de ensino e aprendizagem e assim reduzam o problema que os smartphones causam durante as aulas.

Em alguns casos, os profissionais da educação ainda apresentam certo desconforto em usar as tecnologias móveis como recurso pedagógico. Porém, Carneiro (2002) afirma que essa resistência vai sendo quebrada à medida que as tecnologias vão se tornando cada vez mais familiares e acessíveis, a ponto desses sentimentos de resistência e de idolatria serem substituídos por atos de reflexões críticas necessárias aos avanços dessas tecnologias em sala de aula.

Em alguns estados do país ainda vigora a proibição do uso dos celulares em sala de aula, entretanto existe o Projeto de Lei No 2.547/2007 (BRASIL, 2007), aprovado em três de junho de 2009, decretando, em parágrafo único, que "serão admitidos, nas salas de aula de estabelecimentos de educação básica e superior, aparelhos eletrônicos portáteis, desde que inseridos no desenvolvimento de atividades didático-pedagógicas e devidamente autorizados pelo docente ou corpo gestor". Com isso, fica a cargo da escola e dos professores o uso desses aparelhos em sala de aula para fins pedagógicos.

Com a inserção das tecnologias e o uso da internet, a escola passa por reformulações e os métodos dos professores lecionarem também devem mudar, pois é necessário que os docentes possuam o conhecimento da tecnologia e como usá-la a seu favor na sala de aula, já que grande parte de seus estudantes estão conectados aos avanços tecnológicos.

\# Tear: Revista de Educação Ciência e Tecnologia, v.8, n.2, 2019. 
Segundo Gregio (2004, p. 7),

[...] percebe-se que não é possível estudar o homem pós-moderno sem levar em conta sua inserção em uma sociedade altamente tecnológica. É imprescindível ressaltar que a tecnologia está presente em nosso dia-a-dia, é um processo histórico e não se pode negá-lo e nem pensar em retrocesso, mesmo embora seja um período de transição.

Assim, é fundamental que os professores estejam aptos a inserir essas tecnologias como recurso pedagógico e com isso tornar as aulas mais dinâmicas.

Em relação ao uso de dispositivos eletrônicos e ao acesso à internet pelos brasileiros, o Instituto Brasileiro de Geografia e Estatística (IBGE) divulgou no ano de 2018 os resultados da Pesquisa Nacional por Amostra de Domicílios Contínua (PNAD) em que investigou o acesso à internet e a televisão e posse de telefone móvel celular para uso pessoal para o ano de 2016. Nessa pesquisa, o IBGE destaca que:

Em 97,2\% dos 48070 mil domicílios em que havia acesso à Internet, o telefone móvel celular era utilizado para este fim. Em seguida, substancialmente abaixo, mas passando da metade dos domicílios em que havia acesso à Internet, estava o microcomputador $(57,8 \%)$. O tablet foi usado para esse fim em $17,8 \%$ dos domicílios em que havia acesso à Internet, e a televisão, em 11,7\%. Equipamento diverso foi utilizado para acessar a Internet em 620 mil domicílios, o que representou somente $1,3 \%$ das residências em que houve utilização dessa rede. Como visto, nos domicílios em que havia acesso à Internet, o telefone móvel celular era utilizado para este fim em $97,2 \%$, porém, em $38,6 \%$ deles, somente esse meio era utilizado para acessá-la (IBGE, 2016, p.6).

Com isso, percebe-se a importância do uso dos smartphones para a população brasileira, visto que eles possuem acesso à internet e que esse aparelho móvel dispõe de diversas funcionalidades e informações, facilitando a vida das pessoas. Nesse sentido, a escola não poderá evitar o uso desses dispositivos, até porque fazem parte do cotidiano dos estudantes.

\subsection{Tablets}

Segundo Higuchi (2011, p.31), "atualmente, os tablets são portáteis, permitem conectividade, multimídia e as telas são sensíveis ao toque", o autor afirma que o primeiro tablet surgiu em 1968, mas só começou a ser desenvolvido com a intenção de se tornar um computador-prancheta em 1980. Com o passar dos anos, os tablets foram ganhando cada vez mais funcionalidades, o que antes era possível apenas para os computadores de mesa. Com isso ganharam força no mercado educacional, proporcionando a portabilidade (HIGUCHI, 2011).

Em relação aos tablets, Moran (2013) afirma que eles são mais atraentes, intuitivos, fáceis de manusear e de ler, possuem mais recursos e são mais rápidos quando comparados aos ultrabooks. Porém, esse autor ainda destaca que "os tablets não privilegiam o ato de escrever, fundamental para aprender" (MORAN, 2013, p.31). Isso, no entanto, para o autor, é uma questão de tempo para que os tablets incorporem os melhores recursos dos notebooks mais poderosos.

Algumas escolas já aderiram o uso dos tablets, já que eles podem ser um bom recurso para inserir as tecnologias móveis nas aulas. Os estudantes apreciam a tecnologia que está presente em nosso dia a dia também em sala de aula, os jovens usam o tablet para interagir nas redes sociais, fazer pesquisas, ler um livro e jogar, pois é de fácil manuseio. Crianças

\# Tear: Revista de Educação Ciência e Tecnologia, v.8, n.2, 2019. 
muito pequenas também conseguem usar esse dispositivo, pois a tela sensível ao toque proporciona uma facilidade em usar esse aparelho.

\subsection{Experiências com a utilização de smartphones e tablets em sala de aula}

Atualmente, o uso de smartphones e tablets está cada vez mais presente na sala de aula, pois, os estudantes são inseridos na cultura digital desde muito cedo, fase anterior ao processo de escolarização desses sujeitos. Com isso, é necessário que os professores utilizem esses dispositivos como recurso pedagógico para auxiliar no processo de ensino aprendizagem dos diferentes componentes curriculares, em especial na Matemática, foco desse trabalho.

Nesse sentido, Sanchez (2016) desenvolveu em sua tese um estudo que visa aumentar a eficiência na aprendizagem da tabuada e contribuir para a inclusão de crianças com Transtorno do Déficit de Atenção com Hiperatividade (TDAH). Sanchez (2016) criou um aplicativo móvel para auxiliar alunos do Ensino Fundamental portadores de TDAH a estudar a tabuada. Os estudos dessa pesquisa sobre o ensino da tabuada foram realizados em duas escolas, sendo que o aplicativo foi utilizado em uma delas apenas. O autor destaca que a escola que utilizou o recurso tecnológico obteve resultados mais positivos em relação à escola que não utilizou o software para as aulas de tabuada.

Seguindo a perspectiva do uso de tecnologias móveis no ensino de Matemática, Souza (2017) apresenta em sua dissertação a análise do uso do jogo "Tabuada Espacial", um aplicativo que foi criado pelo autor para auxiliar no ensino da tabuada para alunos dos Anos Iniciais. Os resultados apresentados mostraram que as práticas envolvendo atividades lúdicas podem auxiliar o processo de aprendizagem de Matemática pelos estudantes de forma interativa e divertida.

Freitas e Carvalho (2017) dissertam sobre o uso de tablets e smartphones como recursos didáticos para a aprendizagem dos conteúdos matemáticos, com o objetivo de observar como esses instrumentos podem contribuir na formação inicial de professores que atuarão no Ensino Fundamental. Esse estudo foi realizado com estudantes dos cursos de graduação de Licenciatura em Pedagogia e Matemática.

Os autores destacam que os estudantes mostraram interesse nas possibilidades que o uso das tecnologias móveis como recurso de ensino e aprendizagem dos conteúdos matemáticos por meio de aplicativos pode promover. Também observaram que boa parte da formação inicial desses estudantes é deficitária em relação à abordagem das tecnologias móveis como recursos pedagógicos.

Diante do exposto, nota-se o uso das tecnologias móveis como recurso pedagógico tem boa aceitação por parte dos estudantes e os resultados das pesquisas analisadas mostram que o uso desses recursos pode auxiliar no processo de ensino e aprendizagem de conteúdos matemáticos.

\section{Materiais e métodos}

A pesquisa, da qual este trabalho é oriundo, foi classificada como uma investigação qualitativa uma vez que ela vai além de quantificar o aluno, pois se preocupa com o contexto social em que os participantes da pesquisa estão envolvidos. Nesse sentido, concorda-se com Silveira e Córdova (2009, p.31) quando dizem que "a pesquisa qualitativa não se preocupa

\# Tear: Revista de Educação Ciência e Tecnologia, v.8, n.2, 2019. 
com representatividade numérica, mas, sim, com o aprofundamento da compreensão de um grupo social, de uma organização, etc.”.

A pesquisa foi desenvolvida em uma turma de licenciandos do $6^{\circ}$ semestre do curso de Pedagogia, de uma universidade da região central do Rio Grande do Sul, composta por oito alunas. Considerando os objetivos da pesquisa, propôs-se uma sequência de atividades envolvendo as tecnologias móveis para discutir o ensino da tabuada. Entretanto, esse trabalho, detém-se em uma atividade da sequência, que consistiu na apresentação da atividade envolvendo o jogo Math Duel, o qual apresenta questões envolvendo a adição, subtração, multiplicação e divisão.

O Math Duel é um jogo de Matemática educativo para ser jogado em dupla. Foi desenvolvido e publicado por Peaksel Games, uma empresa de meios digitais situada em Nis, na Sérvia. O acesso ao jogo se dá pelo Play Store ${ }^{3}$. O jogo possui a interface de tela dividida em duas partes para que os dois jogadores possam ocupar apenas um dispositivo. Tem acesso gratuito e é indicado para crianças a partir de cinco anos de idade, sendo que os adultos também demonstram interesse no duelo de Matemática. Foi desenvolvido para ser um estímulo cerebral, pois pode melhorar as habilidades em Matemática, os reflexos e a concentração dos estudantes.

Os jogos do tipo multijogadores, como é o caso desse, estão conquistando a população, porque são jogos de interação entre pessoas e não apenas de uma pessoa e um dispositivo eletrônico. O Math Duel é um jogo que exige dos participantes concentração e reação, fazendo o jogador pensar rápido e de forma correta, pois se tentar adivinhar e responder errado, o jogador vai perder um ponto na partida.

A Figura 1 mostra como o jogo se apresenta para os jogadores; enquanto a Figura 2 mostra dois exemplos de interfaces dos duelos.

Figura 1 - Interface inicial

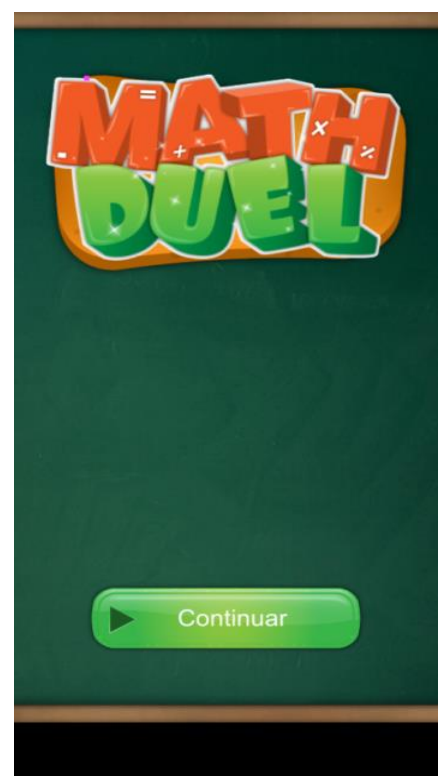

Fonte: Math Duel (2019)
Figura 2 - Interfaces dos duelos
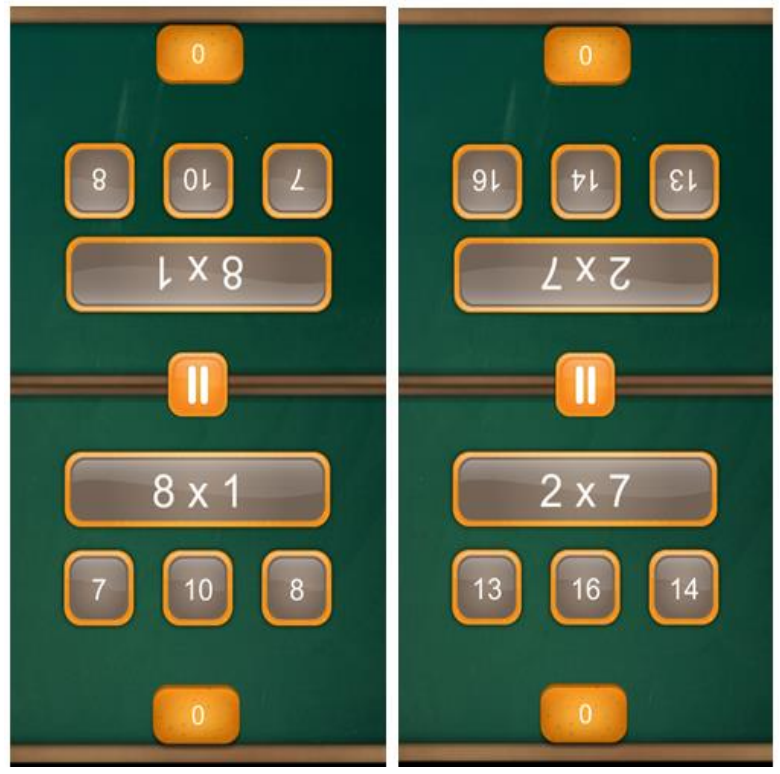

Fonte: Math Duel (2019)

\footnotetext{
${ }^{3}$ Play Store ou Google Play - é um serviço de distribuição digital de aplicativos, jogos, filmes, etc., desenvolvido e operado pela Google.
}

\# Tear: Revista de Educação Ciência e Tecnologia, v.8, n.2, 2019. 
O jogo Math Duel possui quatro níveis de dificuldade: fácil, médio, difícil e muito difícil. Para esta atividade, solicitou-se que as participantes instalassem o jogo no seu smartphone e o manuseassem utilizando as operações de adição, subtração, multiplicação e divisão. Após vinte minutos da exploração do jogo, solicitou-se que as mesmas trabalhassem apenas com a operação de multiplicação, pois é uma das operações envolvidas na tabuada e poderiam jogar os quatro níveis do jogo. Após a exploração do jogo, foi proposto que as participantes respondessem um questionário online (Figura 3) elaborado por nós.

Figura 3-Questionário sobre o jogo

Após explorar e jogar o Math Duel responda as seguintes questões:

1) Você gostou do jogo Math Duel? Por quê?

2) Comente sobre as estratégias que você utilizou durante as jogadas.

3) Você acredita que os jogos digitais podem ser uma boa ferramenta para auxiliar no ensino da Tabuada? Justifique sua resposta.

4) Você utilizaria esse jogo para explorar a Tabuada com seus alunos? Por quê?

Fonte: ROSA; PRETTO; BULEGON, 2019.

Os dados de identificação das participantes foram: nome, idade, escolarização e experiências profissionais. Para preservar a identidade das mesmas, usamos nomes fictícios para a análise dos resultados.

\section{Resultados e discussões}

A atividade foi realizada em duplas, pois o jogo é um duelo. Usou-se essa atividade com o objetivo de verificar como as acadêmicas iriam reagir frente aos jogos digitais e às atividades envolvendo a multiplicação.

O momento destinado à exploração do jogo Math Duel demonstrou ser um momento de descontração do grupo. As licenciandas gostaram de jogar e desafiar as colegas para o duelo. Percebeu-se que esse jogo provocou a interação entre as integrantes da turma. Logo após a exploração do jogo, realizaram-se alguns questionamentos para saber a opinião das participantes sobre a importância do jogo.

Ao serem abordadas se haviam gostado da atividade, a resposta foi $100 \%$ positiva. A turma afirmou que o jogo traz alegria e dinamismo à sala de aula. 
Alguns comentários das estudantes são trazidos, a fim de elucidar seu posicionamento em cada uma das questões propostas. É importante destacar que os nomes utilizados são fictícios, e as estudantes não foram identificadas.

Eduarda, em seu comentário, diz:

Gostei bastante do jogo, por trazer a ideia do duelo, traz bastante dinamismo a atividade, além de proporcionar um pensamento rápido para a solução das operações. Jogar em dupla contribui, porque você fica analisando a reação da outra pessoa também na hora de resolver, e tem que pensar no que é melhor fazer quando não sabe a resposta, arriscar perder pontos ou ficar sem jogar. (informação verbal)

Vale ressaltar que se o participante errar a resposta do jogo perde um ponto, com isso, é necessário construir uma estratégia para responder às questões.

A participante Mariana comentou sobre o jogo

Porque foi um momento divertido e engaçado e também porque ele foi um recurso novo que possibilitou um novo aprendizado, um jogo que permite resolver diversas operações matemáticas. Contribui também para que as pedagogas possam levar para sala de aula e utilizar como um recurso pedagógico para potencializar aprendizagem das 4 operações matemáticas. (informação verbal)

Com esse depoimento, pode-se verificar que as acadêmicas consideram o uso de jogos digitais e dispositivos móveis, como sendo um recurso novo capaz de despertar o interesse dos alunos pela tabuada.

A segunda questão corresponde à explicação das estratégias que as participantes utilizaram durante as jogadas. Observou-se, durante a atividade, que todas gostariam de ganhar a partida do jogo e que, quando isso não ocorria, a frustração era evidente, mesmo se tratando de um público adulto.

\section{Confirmando essa afirmação, Gabriela diz:}

Tentei ser o mais rápida possível na resolução das questões, e quando essas eram mais complexas, pensava um pouco mais. Optei por não tocar nas respostas quando tinha que pensar muito na questão, porque creio que era pior perder pontos do que não ganhar nenhum. No final, tive bons resultados com as minhas estratégias, ganhei a maioria das partidas que joguei. (informação verbal)

Nesse trecho percebe-se algo importante que o professor deve estar atento durante a utilização de um jogo digital: a acadêmica afirma que optou por não responder quando tinha que "pensar muito na questão". Nesse sentido é relevante que o professor conduza os estudantes a algumas reflexões: "será que essa estratégia é a mais correta para o aprendizado? Será que o estudante que fizer mais pontos realmente é o que sabe mais? "Essas são questões para serem analisadas e refletidas quando se fizer de jogos.

A participante Jéssica afirmou que sua estratégia durante as jogadas foi "ter raciocínio rápido para encontrar o resultado antes do oponente, praticando o exercício do cálculo mental de forma rápida e eficaz, de modo a ser mais rápido que meu adversário". O jogo requer agilidade e pensamento rápido por parte dos jogadores, visto que ganha quem obtiver 10 pontos primeiro. Nesse contexto, Ana também pensou em estratégias semelhantes às das colegas, e diz: "tentei ser rápida, porém houve momentos em que me confundi no resultado da multiplicação. Quando era uma multiplicação com mais de dois algarismos eu precisei me concentrar mais" (informação verbal). A capacidade de concentração é fundamental durante as jogadas, pois muitas vezes pode-se saber o resultado da operação, mas, se houver distração e o nosso adversário for mais rápido, perde-se a chance de ganhar um ponto. 
Os níveis de dificuldade do jogo podem ser alterados, intermediando de fácil a muito difícil. O professor deve orientar os estudantes durante a escolha do nível do jogo considerando os conhecimentos prévios que os mesmos possuem.

A terceira pergunta tinha por objetivo verificar a opinião das participantes sobre a utilidade do uso dos jogos digitais no ensino da tabuada em suas futuras aulas.

As participantes, em unanimidade, acreditam que os jogos digitais podem ser uma boa ferramenta para auxiliar no ensino da tabuada, uma vez que os estudantes da Educação Básica estão inseridos nessa realidade e que normalmente utilizam os jogos para entretenimento. Dessa maneira, o professor pode (e deve) propor atividades com o uso desses jogos em sala de aula. A partir desse pensamento, Eduarda comenta que "as tecnologias estão aí, e é necessário que as insertamos na sala de aula. Ignorar a existência delas não é algo que se possa fazer hoje em dia, e os jogos são divertidos, dinâmicos, participativos, e penso que colocam os alunos em uma posição de atividade e pensamento rápido" (informação verbal).

As acadêmicas destacaram, em muitos de seus discursos, que o uso do jogo digital desperta a curiosidade do aluno e instiga-o a participar de uma competição, desenvolvendo habilidades como a concentração e motricidade. A diversão que o jogo proporciona foi evidenciada em diversas conversas entre as participantes, durante a realização da pesquisa. Elas acreditam que isso facilita a inserção dos conteúdos matemáticos nas séries iniciais. Eduarda cita que "as crianças gostam de "brincar" e o estilo do jogo apresentado, incentiva a criança a estudar em casa, pois pode baixar o jogo no seu próprio celular, uma vez que ele está disponível gratuitamente na Internet" (informação verbal).

Os jogos podem auxiliar no processo de aprendizagem, porém não dispensam o acompanhamento e orientação do professor, pois o estímulo gerado nos jogadores pode causar distração e não potencializar a aprendizagem. Os recursos tecnológicos podem chamar a atenção dos estudantes, já que a maioria deles já está acostumada a conviver com essa tecnologia em todos os lugares. Diante disso, Mariana destaca:

\footnotetext{
Os jogos digitais são uma ótima ferramenta para o ensino da tabuada e de outros conteúdos. É relevante também para os alunos incluídos, porque com o uso das tecnologias temos mais opções e diversas maneiras de adaptar o conteúdo, com isso considero importante o uso dos jogos digitais nas aulas em todas as disciplinas. (informação verbal)
}

Em muitas escolas o uso dos smartphones é restrito, pois alguns profissionais da educação temem que os estudantes não façam uso para fins pedagógicos. No entanto, alguns professores defendem o seu uso na sala de aula, como, por exemplo, a participante Ana destaca: "usar o celular a favor do ensino pode ser uma alternativa para desmistificar a fama que o mesmo tende a atrapalhar o aprendizado e o desenvolvimento de conteúdos em sala de aula". Concorda-se com o posicionamento de Ana, em vista que o professor deve combinar e monitorar o que os estudantes irão fazer ao usar os smartphones ou tablets. Precisa-se alertar para os perigos que existem na Internet, sendo fundamental que os estudantes tenham em mente o objetivo da atividade que vão realizar usando essa tecnologia.

Para finalizar o questionário sobre o jogo Math Duel, foi questionado se as participantes utilizariam esse jogo para explorar a tabuada com seus alunos e por quê. Foi evidente a aceitação de todas as participantes da pesquisa, com depoimentos de como o jogo

É muito divertido, traz elementos contundentes no estudo da tabuada e, além disso, traz a diversão, o que contribui para a aprendizagem de Matemática desde pequeno. É um bom jogo, e o utilizaria sim (EDUARDA). 
Já usei inclusive. Foi um sucesso. Eles aprendem a resolver as operações de uma forma rápida, estimulando o cálculo mental, e se divertem muito (JÉSSICA).

Na segunda feira após conhecer o jogo, eu já o explorei com um aluno com hipótese de autismo, em que eu consegui obter um envolvimento dele no jogo e uma maneira de atrair a atenção e concentração dele porque gosta bastante de jogo (ANA). (informação verbal)

A partir dos depoimentos mencionados, conclui-se que a escolha e utilização desse jogo foi positiva e que contribuiu para a formação inicial de algumas pedagogas acerca do conceito de tabuada.

\section{Considerações Finais}

Atualmente, vive-se em uma sociedade em constante mudança, verificada, principalmente, devido ao desenvolvimento da tecnologia. A escola não pode ignorar essas mudanças, pois o perfil dos estudantes acompanha o processo de inserção das tecnologias na sociedade. Por isso, o professor deve estar atento às especificidades que os estudantes manifestam e propor situações de aprendizado onde ele possa usar os conhecimentos que já possui para adquirir novos conhecimentos.

O objetivo desse trabalho era investigar as percepções de um grupo de acadêmicas de um curso de Pedagogia sobre o uso do jogo Math Duel como ferramenta para o ensino da tabuada. Ao interagir com o jogo, as participantes demonstraram motivação, alegria e satisfação em manuseá-lo, mesmo aquelas participantes que não estavam acostumadas a usar as tecnologias móveis em atividades escolares.

$\mathrm{Na}$ visão dessas acadêmicas, podem-se utilizar jogos digitais para desenvolver e/ou verificar a aprendizagem dos conceitos de tabuada, pois depois de experimentarem o jogo algumas fizeram uso dele com seus estudantes de anos iniciais do Ensino Fundamental. Relataram que eles se envolveram completamente com o jogo, pois o mesmo é divertido e estimula o cálculo mental, o que permite aprender e resolver as operações da tabuada de forma rápida e eficaz.

Diante dessas evidências, pode-se dizer que os jogos digitais despertam a atenção e concentração dos estudantes, a partir do envolvimento deles em cada fase/etapa, e o sucesso obtido em cada uma delas gera satisfação, o que potencializa a aprendizagem da tabuada para além dos espaços escolares.

\section{Financiamento e agradecimentos}

O presente trabalho foi realizado com o apoio da Coordenação de Aperfeiçoamento de Pessoal de Nível Superior - Brasil (CAPES) - Código de Financiamento 001.

\section{Referências}

ARAÚJO, J. L. Tecnologia na Sala de Aula: desafios do professor de matemática. In: ENCONTRO DE EDUCAÇÃO MATEMÁTICA DE OURO PRETO ENCONTRO DE EDUCAÇÃO MATEMÁTICA DE OURO PRETO, 3, 2005, Ouro Preto. Anais [...]. Ouro Preto, 2005. Disponível em: http://www.mat.ufmg.br/ jussara/artigos/Araujo\%20(2005).pdf . Acesso em: 17 maio 2018. 
BRASIL. Instituto Brasileiro de Geografia e Estatística. Pesquisa Nacional por Amostra de Domicílios Contínua: acesso à Internet e a televisão e posse de telefone móvel celular para uso pessoal. 2016. Disponível em:

https://biblioteca.ibge.gov.br/visualizacao/livros/liv101543.pdf . Acesso em: 20 maio 2018.

BRASIL. Projeto de Lei PL 2.547/2007. Brasília, DF: Câmara do Deputados, 2007. Disponível em: https://www.camara.leg.br/proposicoesWeb/prop_mostrarintegra;jsessionid=8FDA1DB53 D159652F14B9597FE30BFC5.node1 ?codteor=535313\&filename=Avulso+PL+2547/2007 . Acesso em: 17 maio 2018.

CARNEIRO, R. Informática na educação: representações sociais no cotidiano. São Paulo: Cortez, 2002.

FREITAS, R. O.; CARVALHO, M. Tecnologias móveis: tablets e smartphones no ensino da matemática. Laplage em Revista, Sorocaba, v. 3, n.2, maio/ ago., 2017, p.47-61. Disponível em: http://www.laplageemrevista.ufscar.br/index.php/lpg/article/download/341/508 . Acesso em: 28 mar. 2019.

GREGIO, B. M.A. A Informática na Educação: as Representações Sociais e o Grande Desafio do Professor Frente ao Novo Paradigma Educacional. In.: Colabor@ - Revista Digital da CVA, Ricesu, v. 2, n. 6, p. mar. 2004. Disponível em:

http://pead.ucpel.tche.br/revistas/index.php/colabora/article/viewFile/43/39 . Acesso em: 20 maio 2018.

GOUVÊA, A.E. S.; PEREIRA, E. M. O uso de Tecnologia Móvel: celular como apoio pedagógico na escola. In: COLÓQUIO DE LETRAS, 2., 2015, Breves. Anais [...]. Breves: FALE/CUMB, 2015. Disponível em: http://www.coloquiodeletras.ufpa.br/downloads/iicoloquio/anais/41-antonio-emilson.pdf . Acesso em 17 maio 2018.

HIGUCHI, A.A.S. Tecnologias Móveis na Educação. 2011. 90f. Dissertação (Mestrado em Educação Arte e História da Cultura) - Universidade Presbiteriana Mackenzie, São Paulo, 2011.

IMBERNÓN, F. Formação docente e profissional: formar-se para a mudança e a incerteza. 2011. 9 ed. São Paulo: Cortez.

MORAN, J. M. Ensino e aprendizagem inovadores com tecnologias. In: MORAN, J. M.; MASETTO, M. T.; BEHRENS, M. A. Novas tecnologias e mediação pedagógica. 21 ed. Campinas: Papirus, 2013. p. 11-66.

PENTEADO, M. Possibilidades para a Formação de Professores de Matemática. In: PENTEADO, M. G.; BORBA, M.C. (org.). A informática em ação: formação de professores, pesquisa e extensão. São Paulo: Olho d'Água, 2000. p. 23-34. Disponível em: http://www.rc.unesp.br/gpimem/downloads/livro/infoacao.pdf . Acesso em: 18 maio 2018.

RECCHI, A. M. S.; MARTINS. M. M. A produção de materiais didático-digitais como ferramenta auxiliadora no processo de ensino-aprendizagem na área de ciências da 
natureza. CCNEXT - Revista de Extensão, Santa Maria, v.3, Ed. Especial, 2016, p. 294300.

RODRIGUES, G. R. Smartphones e suas tecnologias. 2009. Trabalho de Conclusão de Curso (Bacharelado em Engenharia Elétrica) - Escola de Engenharia de São Carlos, Universidade de São Paulo. 2009. Disponível em:

www.tcc.sc.usp.br/tce/disponiveis/18/.../tce.../Rodrigues_Guilherme_Rodrigues_e.pdf . Acesso em: 18 maio 2018.

ROMANELLO, L. A. O celular como recurso didático nas aulas de Matemática: a visão do professor. In: ENCONTRO BRASILEIRO DE ESTUDANTES DE PÓS-GRADUAÇÃO EM EDUCAÇÃO MATEMÁTICA, 20., 2016, Curitiba. Anais [...]. Curitiba: UFPR. Disponível em:

http://www.ebrapem2016.ufpr.br/wpcontent/uploads/2016/04/gd6_la\%C3\%ADs_romanell o.pdf . Acesso em: 20 maio 2018.

SANCHEZ, W. M. Aplicativo móvel para auxiliar alunos do Ensino Fundamental portadores de TDAH no aprendizado da Tabuada. 2016. Tese (Doutorado em Engenharia Biomédica) - Universidade de Mogi Das Cruzes, Mogi das Cruzes. 2016.

SILVEIRA, D. T.; CÓRDOVA, F. P. A pesquisa científica. In: GERHARDT, T. E.; SILVEIRA, D. T. (org.). Métodos de pesquisa. Universidade Aberta do Brasil UAB/UFRGS e Curso de Graduação Tecnológica - Planejamento e Gestão para o Desenvolvimento Rural da SEAD/UFRGS. Porto Alegre: UFRGS, 2009. p. 31-42.

SOUZA, D.O. Ensino de Matemática com o uso das TIC. 2015. Trabalho de Conclusão de curso (Especialização em Mídias na Educação) - Centro Interdisciplinar de Novas Tecnologias na Educação, Universidade Federal do Rio Grande do Sul. 2015. 41 f. Disponível em:

https://www.lume.ufrgs.br/bitstream/handle/10183/133978/000979603.pdf? sequence=1 . Acesso em: 18 maio 2018.

Recebido em abril de 2019.

Aprovado em outubro de 2019. 